\title{
VOCALIZATIONS AND ASSOCIATED BEHAVIORS OF THE SOMBRE HUMMINGBIRD (APHANTOCHROA CIRRHOCHLORIS) AND THE RUFOUS-BREASTED HERMIT (GLAUCIS HIRSUTUS)
}

\author{
Adriana R. J. Ferreira ${ }^{1,2}$, Tom V. Smulders ${ }^{3}$, Koichi Sameshima ${ }^{4}$, Claudio V. Mello ${ }^{5}$, and \\ Erich D. Jarvis ${ }^{1,6}$ \\ 1 Department of Neurobiology, Duke University Medical Center, Box 3209, Durham, North Carolina 27710, \\ USA
}

2 Instituto de Psicologia, Programa de Neurociências e Comportamento, Universidade de São Paulo, São Paulo, SP, Brazil

3 School of Biology, University of Newcastle upon Tyne, Newcastle upon Tyne NE1 7RU, United Kingdom

4 Departamentos de Patologia e Radiologia, Faculdade de Medicina, Universidade de São Paulo, São Paulo, SP, Brazil

5 Neurological Sciences Institute, Oregon Health and Science University, West Campus, 505 N.W. 185th Avenue, Beaverton, Oregon 97006, USA

\begin{abstract}
Vocal behavior in tropical hummingbirds is a new area of study. Here, we present findings on the vocalizations and associated behaviors of two species: Sombre Hummingbird (Aphantochroa cirrhochloris) and Rufous-breasted Hermit (Glaucis hirsutus). These are the only hummingbirds in which the brain areas activated by singing have been demonstrated. They are also among the basal species of their respective subfamilies, Trochilinae and Phaethornithinae and, thus, represent early stages in the evolution of hummingbird vocal communication. We found that the two species exhibit distinctive vocalizations and behaviors. Sombre Hummingbird calls had more modulation and were often used during agonistic interactions, whereas Rufous-breasted Hermit calls had higher pitch and purer tones and were produced in less aggressive interactions. Sombre Hummingbird song was highly stereotyped in syllable structure and syntax, whereas Rufous-breasted Hermit song was highly variable. Comparative analysis points to consistent similarities in use of vocalizations by the Sombre Hummingbird and other trochilines, and by the Rufous-breasted Hermit and other phaethornithines. We hypothesize that differences in vocal behavior between hummingbird lineages arise as adaptations to their foraging strategies.
\end{abstract}

\section{Keywords}

Aphantochroa cirrhochloris; Glaucis hirsutus; Rufous-breasted Hermit; Sombre Hummingbird; syntax; territorial; vocal learners

Hummingbirds (Apodiformes: Trochilidae), with 328 recognized species, compose one of the largest bird groups in the Americas (Schuchmann 1999). About 90\%, including all

\footnotetext{
${ }^{6}$ Address correspondence to this author. E-mail: jarvis@neuro.duke.edu.

Associate Editor: K. Yasukawa
} 
phaethornithine species, are in the tropics. Tropical hummingbirds have been the subject of ecological studies that have focused largely on their interactions with plants (Buzato et al. 2000 , Ornelas et al. 2004). By contrast, their vocal behavior is largely unstudied, with only one detailed study on acoustic structure, syntax, and behavioral context of calls and song (Ornelas et al. 2002) and few such studies on songs (Snow 1968, Wiley 1971, Gaunt et al. 1994). Here, we studied the vocalizations and associated behaviors of two tropical species: the Sombre Hummingbird (Aphantochroa cirrhochloris) and the Rufous-breasted Hermit (Glaucis hirsutus). In these species, brain areas active in singing have been mapped (Jarvis et al. 2000). Thus, understanding their vocal behavior will allow future investigations to link behavior with brain function in hummingbirds. Moreover, on the basis of plumage and genetic characteristics, they are believed to be among basal species of the two hummingbird subfamilies, Trochilinae and Phaethornithinae, respectively (Hinkelmann and Schuchmann 1997, K. L. Schuchmann pers. comm.) and, thus, may be useful for understanding the evolution of hummingbird vocal communication.

\section{Methods}

\section{Study Species and Area}

The Sombre Hummingbird is grayish and slightly sexually dimorphic in body size (males are larger; Grantsau 1988). It inhabits gardens and forests of mideastern Brazil, breeds from September to March, and is highly territorial year-round (Ruschi 1964, 1982; Schuchmann 1999). The Rufous-breasted Hermit is green-bronze-brownish, has a long-curved beak with yellow mandible, and is slightly sexually dimorphic in feather coloration and bill shape (Grantsau 1988). It inhabits dense forests of South and Central America and breeds from September to February (Ruschi 1964, Snow 1973, Schuchmann 1999). We studied these two species at the Museu de Biologia Professor Mello Leitão (MBML) in Santa Teresa, Espírito Santo state $\left(40^{\circ} 60^{\prime} \mathrm{W}, 19^{\circ} 93^{\prime} \mathrm{S}\right)$, Brazil, a mountainous Atlantic Forest region $656 \mathrm{~m}$ above sea level.

\section{Behavioral Scoring and Recording of Vocalizations}

We conducted behavioral scoring sessions eight days per month (spread out over the month), at three times: 0630-0730 hours, 1100-1200 hours, and 1600-1700 hours (EST) in October 1997, from June 1998 to February 1999, in July 1999, and from January to June 2000. Half of each session was dedicated to each species. Species order was decided randomly and used for all sessions that day. Sites included areas near feeders (24\% glucose; next to forest vegetation), flowerbeds away from feeders, and wooded areas near walking trails away from feeders.

Feeders were filled twice each day. The site was also decided randomly and used for all sessions that day. At each session, we focused on one arbitrarily chosen individual and scored its actions every time a vocalization was produced until the end of the session or until the individual disappeared. At weekly intervals, we made audio recordings with a Tascam DP-1 digital recorder and video-audio recordings with a Sony VXR-1000 digital camcorder, both attached to a Sennheiser ME62 cardioid microphone in a Telinga parabola $(58 \mathrm{~cm})$. Sounds were computer digitized and spectrograms made with either Macromedia SOUNDEDIT 16, version 2 (Adobe, San Jose, California; settings 6-48 dB gain and Hamming algorithm filter) or AVISOFT (Raimund Specht, Berlin; settings FFT length 256, Frame 100\%, and Hamming algorithm filter with 50\% overlap). We used GOLDWAVE (GoldWave, St. John's, Newfoundland) to remove excess noise below $500 \mathrm{~Hz}$, and then analyzed acoustic features with SOUND ANALYSIS, version 1.4 (Tchernichovski et al. 2000). Spectrograms, vocalizations, and pictures are available at the Jarvis lab's website (see Acknowledgments). Recordings are deposited at the Borror Laboratory of Bioacoustics (The Ohio State University, Columbus, Ohio). 


\section{Definitions}

Acoustic features_-Duration": Amount of time a vocalization lasts. "Pitch": Fundamental frequency of a sound. "Wiener entropy": Unitless measure of randomness in a sound, on a logarithmic scale ranging from 0 to minus infinity; white noise has high entropy $(\log 1=0)$, and pure tone has low entropy ( $\log 0=$ minus infinity). "Frequency modulation" (FM): Slope of frequency contours over time ( $0-90^{\circ}$ from the horizontal axis). "Continuity": Unitless measure of continuity of frequency contours across time (ranges from 0 to $1 ; 1$ is the most continuous).

Vocalizations_-"Syllable" or "syllable type": Short vocalization lasting usually $<500 \mathrm{~ms}$ and limited by silence. "Syllable class": Variant forms of a syllable type grouped together according to the number of harmonics and level of modulation. "Call" or "call type": Vocalization composed of a unique syllable type or syllable class produced once or in bouts. "Song": Continuous series of vocalizations consisting of different syllable types or classes produced in close succession. "Song bout": Continuous production of song followed by a long silent interval. "Song motif": Repeated sequence of syllables in a song bout.

Territory-We define "territory" as follows. For Sombre Hummingbird, this was an area no larger than a midsize tree, near flower beds or feeders, where a bird would attack another bird if the other entered or attempted to feed in that space. Territories can be overlapping. For Rufous-breasted Hermit, we did not note this type of territorial behavior.

Individual identification-We used one of three methods. (1) Birds were recorded and subsequently sacrificed for analysis of brain vocal nuclei (Jarvis et al. 2000). (2) Birds were observed singing and were captured, and a spot of their ventral plumage was labeled with one color of a toy-model paint (red, blue, yellow, etc.). This method of labeling was used in previous studies with hummingbirds (Wolf 1969, Wolf and Stiles 1970) and apparently does not effect the birds' behavior. (3) Short-term observations (one day) were made of birds perched in different sites. On any given day, we were able to identify six or more Sombre Hummingbirds and up to four Rufous-breasted Hermits at their perch sites.

Syntax diagrams-We generated song syntax diagrams with an approach modified from Ficken et al. (2000). We aligned and letter-coded sequences of syllables from 5-12 song bouts per bird, labeling syllables or syllable types in the order in which they appeared (i.e., silence$A-B-C \ldots$ ). We then determined the total number of each transition type (i.e., $A-A, A-B \ldots$ ) across all bouts and divided that number by the total number of all transitions, thus obtaining the relative transition occurrence values ( $\left.T_{\text {occurrence }}\right)$ for each transition type ( 1 being the sum of values for all transition types across the $5-12$ bouts):

$$
T_{\text {occurrence }}=\frac{\text { total number of occurrences of a transition type }}{\text { total number of occurrences of all transition types }}
$$

With the $T_{\text {occurrence }}$ values, we created syntax diagrams, with arrow thickness proportional to the values. Arrows that curve backwards from the end to the beginning of a sequence represent repeated motifs. Vertical arrows pointing to horizontal lines designate bout stop-points.

\section{Result}

\section{Sombre Hummingbrid}

Call structure and contexts-We identified six call types, which we named according to sound and spectrogram structure (Fig. 1A-F). The birds vocalized with their beaks closed. The "chirp," "guttural," "vibrato," and "whistle" calls were produced by birds at nest sites (presumably females, given that parental care is a female function in most hummingbirds; 
Schuchmann 1999) and by birds that sang (presumably males, given that only males have been found to sing; Jarvis et al. 2000). The "crack" and "high-pitch" calls were produced by birds also observed singing, and therefore are likely produced by males. The chirp call consisted of a harmonic stack with a slight rise, and then a longer and marked drop in frequency (Fig. 1A). It was relatively short in duration, high in pitch, and continuous (Figs. 1A and 2). It was the most commonly produced vocalization (Table 1), always in bouts, while a bird was perched, and was either undirected or directed toward approaching birds. When undirected, it was continuously produced (intersyllable intervals ranging from 150 to $250 \mathrm{~ms}$ ) for seconds or minutes. The bird usually had a relaxed body posture, sometimes stretching its wing. When directed toward approaching conspecifics or individuals of other hummingbird species that entered a bird's feeding area, the perched bird would often increase the production rate and assume an alert posture (body upright and tail closed) until the intruder left. If the intruder did not leave, the perched bird often became excited, tilted its body forward in a threat display (wings partly spanned open, body and head tilted forward with tail half-open, and body shaking), chirped at a higher rate (Fig. 1G, first six calls), and attacked. When the intruder left, the bird often went back to its perch, produced a steady series of chirps, and gradually stopped vocalizing (Fig. 1H). Outside of our behavioral scoring sessions, the chirp call was produced, along with those of other hummingbird species, when the birds were mobbing large intruders (other birds and squirrels) that entered the feeding area (feeders or flower beds).

The guttural, vibrato, and crack calls were the next-most-commonly produced nonwhistle calls (Fig. 1B-D) and were usually produced when flying and in highly aggressive contexts (Table 1). The guttural call (Fig. 1B) sounded like a "grr" and was variable in duration, low in pitch, disordered, modulated, and discontinuous compared with most other calls (Fig. 2). It was produced almost exclusively when birds were expelling other birds from their immediate territory. The vibrato call (Fig. 1C) sounded like a brief cricket song and was more variable in pitch, disordered, and highly modulated (Fig. 2). It was produced mainly during expulsions and direct confrontations (Table 1), but also during courtship (see below). The crack call (Fig. 1D) resembled the guttural call in shape and acoustic features but was shorter in duration (Figs. 1 and 2). It was one of the most rarely produced calls (Table 1).

Whistle calls sounded similar between renditions from the same and across different birds, but spectrograms revealed a variety of forms (Fig. 1E). Some had little modulation (pure whistle call), others a small vibrato (vibrato whistle call), and others two sounds with different structures (nonharmonic whistle call), which suggests independent and simultaneous production of two voices by opposite sides of the syrinx (Suthers 1997). Despite these spectrographic differences, there were no detectable differences in the five acoustic features measured (Fig. 2). Whistle calls were longer, higher pitched, purer, less modulated, and highly continuous compared with most other calls (Fig. 2). Most were produced while a bird was perched (Table 1), and they were sometimes accompanied by a threat display directed to another bird, or were produced during courtship. The high-pitch call was the highest-pitched nonwhistle vocalization (Fig. 1F), but had acoustic features similar to whistles, though shorter in duration (Fig. 2). It was the rarest call, observed mainly in aggressive contexts (Table 1), coincident with the end of a fight. Thus, it may serve as an appeasement.

Different call types were produced in sequences mainly in situations of agonistic interactions. For example, after producing the chirp call in a rapid sequence directed at an intruder, a bird flew, producing a vibrato whistle call, and then conducted an aerial fight while emitting guttural calls, all in rapid succession (Fig. 1G). In another example, a bird produced the chirp call while taking off to expel an intruder (Fig. 1I), and the whistle call while flying toward the intruder, and transitioned so rapidly from one call type into another that they seemed fused. 
Song structure and contexts-We identified a basic song composed of six syllable types that we designated $i$ (introductory syllable), $A, B, C, D$, and $E$, with $D$ and $E$ repeated (Fig. 3). The song sounded like a high-pitched, piercing vibrated whistle ( $i$ syllable) followed by a series of soft, fluid, rhythmic vocalizations (repeated $D-E$ syllables). Syllable categorization was determined visually from sonograms by two independent observers, with $100 \%$ agreement. Syllables differed in nearly all acoustic features, but were relatively uniform among birds (low SE; Fig. 4). In syllables $A$ through $E$, spectrograms revealed two sets of modulated overlapping harmonics (Fig. 3), which again suggested independent and simultaneous production of two voices by the syrinx. Song was produced in two contexts: while perched and undirected, nearly the exclusive context (Table 1); or directed while hanging onto another bird's crissum (i.e., the region around the cloaca). Undirected singing was produced during the dawn chorus, with decreasing frequency throughout the day, often when the bird returned to its principal perch after an aggressive encounter. During directed song, an individual hung from a perched bird by grabbing the feathers and skin of that bird's crissum with its beak, made semicircular movements without flapping its wings, and sang in this position (Fig. 5A), while the perched bird uttered one or more whistles (Fig. 5B). Both birds then produced what appeared to be aggressive interactions, in the air, while emitting vibrato calls (Fig. 5B). We observed similar behaviors in a captured female (determined later by gonad examination) in an outdoor aviary. A free-ranging conspecific grabbed the female's crissum with his beak through the aviary wall and simultaneously sang, while the female produced whistles that were interspersed with and sometimes overlapped the male's songs. Therefore, it is likely that the free-ranging female vocalizes the whistle calls in response to a male's directed song, as part of a courtship interaction. The only difference between the directed and undirected songs was the lack of the introductory $i$ syllable in the former.

Song syntax-The basic undirected-song syntax was $i A B C(D E)_{n}(n=$ number of repeated $D$ and $E$ syllables; Fig. 6). The $D-E$ repeats represent the most frequent transition (Fig. 6A, $\mathrm{B})$, followed by the $A-B-C-D$ segment. In all birds, there were small variations on this theme, such as the $i-D$ and $C-A$ transitions (Fig. 6A, B). Larger variations were in song-bout length across birds (not shown). In general, birds produced one or two $i$ syllables, then a stereotyped $A B C(D E)_{n}$ motif with one to seven $D-E$ repeats; then they either stopped singing (most commonly after the $D$ syllable) or began one or more $A B C(D E)_{\mathrm{n}}$ motifs with $D-A$ transitions between motifs, totaling sometimes up to four motifs in a bout.

\section{Rufous-breasted Hermit}

Call structure and contexts-We identified three call types in the Rufous-breasted Hermit population, which we named according to sound and spectrogram structure (Fig. 7A-D). Birds of this species opened and moved their beaks while vocalizing. Their chirp call was highly continuous and had ascending frequency modulation, a fundamental frequency and harmonic, a high pitch, and relatively pure Wiener entropy (Figs. 7A, B and 8). The birds produced single chirps (S-chirp; Fig. 7A) and multisyllable chirps (M-chirp; four to eight syllables of the same class produced in quick succession; Fig. 7B). The S-chirp call was a soft, quick, high-frequency vocalization. It was the most common call (Table 2 ), mainly vocalized while the bird was flying or foraging-flying, once in short-distance flights $(2-3 \mathrm{~m})$ or repeated at long intervals $(\sim 2 \mathrm{~s})$ in longer-distance flights ( $>3 \mathrm{~m}$ ). The M-chirp call sounded like a quick descending series of high-pitch syllables (Fig. 7B). It was observed mostly while perched-directed (Table 2), accompanied by the up-and-down waving of the tail, and often in response to the vocalizations (S- or M-chirp, or song) of another bird that was flying or perched nearby (Table 2).

The transitional call consisted of five to seven syllables of the same class, with complex structural changes from a u-shape to a harmonically enriched v-shape form (Fig. 7C). These transitions were more abrupt in pitch, entropy, and continuity than for the M-chirp call (Fig. 
8). The transitional call was produced in more varied contexts, mostly during agonistic chases (Table 2). Unlike both the S- and M-chirp calls, the transitional-call chases were observed near feeders and flowers; they were directed at either con- or heterospecifics. At the feeders, the general behavior of Rufous-breasted Hermits was passive; they usually waited for others (conor heterospecifics) to feed first. However, after several episodes of being expelled from one or more feeders, a Rufous-breasted Hermit would produce the transitional call while assuming a more aggressive forward posture, allowing it more access to the food. The Rufous-breasted Hermit's guttural call (Fig. 7D) was rarely produced and was never observed within the set behavioral recording periods. It was produced while trying to expel others from feeders. In sound and spectrographic structure, this call was very similar to the comparable guttural call of Sombre Hummingbirds (Figs. 1B and 2).

Individual Rufous-breasted Hermits did not produce call sequences alone, but rather with conspecifics in a coordinated call-and-response pattern. As an example, two birds perched $\sim 50$ $\mathrm{m}$ apart emitted their S-chirp calls three times each in call-and-response. One then vocalized an M-chirp call, the other flew over, and both started a long chase while vocalizing transitional calls. The birds then hovered to face each other, and one exhibited its plumage while producing a transitional call. They then perched close together and repeated the entire process for several minutes. This behavior is akin to the courtship display described for this species (Snow 1973, Ruschi 1982).

Song structure and contexts-Rufous-breasted Hermit song contained many different syllables, which transitioned across syllable types without distinct categorical boundaries (Fig. 9). To classify syllable types, we examined spectrographic recordings from four individuals (4-6 songs per individual) to find syllables that could be unambiguously distinguished. We found seven basic syllable types that we named and ordered $A$ to $G$ based on the number of harmonics and level of modulation (Fig. 10; first syllable of each row). We then placed all the other syllables into classes $A$ to $G$ according to their structural similarity to these basic types (Fig. 10). If a syllable contained features of two classes, it was assigned to the class with which it shared more features. This visual categorization was performed by two independent observers, with $\sim 90 \%$ agreement. Within a song, most syllables transitioned within a type and across types in a gradual fashion, in what we perceived as rolling sequences of ascending and descending frequency: high-pitch syllables that were almost whistles (few harmonics), lowpitch syllables sounding like kisses (many harmonics), back to high-frequency syllables, and so on, in songs whose duration ranged from 2 to $20 \mathrm{~s}$ (Fig. 11A). Calculations of syllable features confirmed this impression and revealed that syllables of the same class differed less in acoustic features than across classes, with $E$ syllables showing the most extreme range of changes in all features except FM (Fig. 11B). Rufous-breasted Hermit song syllables were 23 times longer, were higher in pitch, and had more continuity than Sombre Hummingbird song syllables $(t$-test; $\mathrm{df}=208$ and 756, $P=<0.001, n=4$ birds per species; all syllable classes compared).

Song was produced year-round, nearly exclusively while birds were perched, and was almost always undirected (Table 2). Outside of the scoring periods, directed singing was observed four times. In each instance, a perched bird sang when a female conspecific perched nearby. After singing directed song for some minutes, the singer chased the female for several more minutes. During these chases, transitional calls were produced. Therefore, the percheddirected song appears to be part of courtship.

Song syntax-Rufous-breasted Hermit song syntax had a plethora of different types of transitions within and across syllables types (Fig. 12). The most common were loops within a syllable class, such as $A-A$ and $B-B$; the least common were transitions between some syllables classes, such as $A$ to $D$ (Fig. 12A, B). There were no noticeable introductory-like syllables. 
These general properties were consistent across birds (Fig. 12A, B) and time (three years of recordings). To extract a basic pattern, we calculated the $T_{\text {occurrences }}$ from a group of four randomly chosen birds and found a total of 49 transition types $(A-A, A-B$, etc.). Those that occurred $>1 \%(0.01)$ of the time were arbitrarily considered common; 16 of the 49 met this criterion. Graphing these 16 in a syntax diagram in the closest possible representation of how the songs were produced in time (Fig. 12C) indicated that song had syntactic syllables and segments that matched some calls. The segment with which the birds most often began a song corresponded to the M-chirp call (A class syllables), sometimes followed by looping through the transitional call ( $E$ class syllables), then to one or several $B$ syllables, back to the M-chirp call, to an $A-B-D$ loop series unique to song, through several guttural calls ( $G$ class syllables), back to one of the other loops, ending on a variety of different syllables types (no ending transition occurred $>1 \%$ of the time and, thus, none is shown in the basic syntax diagram).

\section{Disscussion}

Our study provides the first detailed description of the acoustic and syntactic structures of vocalizations and associated behaviors of the Sombre Hummingbird and Rufous-breasted Hermit. Below, we discuss our findings in comparison with vocal behavior of other hummingbirds.

Sombre Hummingbird and Rufous-breasted Hermit syllables differed markedly in acoustic features. Sombre Hummingbird calls were more modulated, whereas the Rufous-breasted Hermit's were higher pitched and purer. Sombre Hummingbird song syllables were 2-3 times longer, whereas the Rufous-breasted Hermit's were more variable; for example, Rufousbreasted Hermit pitch range was wider $(<1$ to $6 \mathrm{kHz})$ than that of the Sombre Hummingbird $(2-4 \mathrm{kHz})$. These acoustic differences are presumably controlled by the anatomical and functional characteristics of the syrinx and vocal tracts, as well as by beak movements (Gaunt 1983, Suthers 1997, Hoese et al. 2000). The latter, as demonstrated in songbirds, change acoustic properties of the vocal tract, filtering or suppressing harmonics of fundamental frequencies (Hoese et al. 2000). Therefore, beak movements might give Rufous- breasted Hermit vocalizations purer tonal quality, wider spectrum, and smooth transitions from one syllable class to another. The Sombre Hummingbird, vocalizing with its beak closed, does not show such characteristics. For Sombre Hummingbird, however, nearly all song and some call syllables are likely to be produced by the two-voice syrinx mechanism (Suthers 1997). The presence of two voices has previously been shown for a hummingbird (Vielliard 1983) and several non-hummingbird avian species (Collias 1987, Guyomarc'h and Guyomarc'h 1996, Suthers 1997, Vallet et al. 1998, Aubin et al. 2000). In two species tested, it functions for sexual attraction (Vallet et al. 1998) and individual identity (Aubin et al. 2000).

Sombre Hummingbird song syntax is simpler and more stereotyped than that of Rufousbreasted Hermit. Interestingly, two other trochilines, the Anna's Hummingbird (Calypte anna; Baptista and Schuchmann 1990) and the Blue-throated Hummingbird (Lampornis clemenciae; Ficken et al. 2000), also have stereotyped song syntax. By contrast, the Saw-billed Hermit (Ramphodon naevius), a close relative of the Rufous-breasted Hermit (Hinkelmann and Schuchmann 1997), has variable syntax and syllable types that are remarkably similar to those of the Rufous-breasted Hermit (sonograms available at the Jarvis lab's website; see Acknowledgments). This similarity among members of the same subfamily is not an absolute rule, because the song of the Scale-throated Hermit (Phaethornis eurynome), a phaethornithine, has stereotyped syntax (sonograms available at the Jarvis lab's website). Nevertheless, our results suggest that complex syntactic organization is not as rare in hummingbirds as previously believed (Ficken et al. 2000). The reason may be that the Sombre Hummingbird, Rufousbreasted Hermit (Jarvis et al. 2000), Anna's Hummingbird (Gahr 2000), and other hummingbird species (Jarvis et al. 2000) have specialized cerebral vocal nuclei for song 
production similar to those of songbirds and parrots. In songbirds and parrots, these nuclei are responsible for vocal learning (Nottebohm et al. 1976, Jarvis 2004) and for complex syntactic organization of these vocalizations (Scharff and Nottebohm 1991, Kobayashi et al. 2001), and they are active in singing (Jarvis and Nottebohm 1997, Jarvis and Mello 2000), as they are in hummingbirds (Jarvis et al. 2000).

Sombre Hummingbirds and Rufous-breasted Hermits differed markedly in vocal behavioral contexts. Sombre Hummingbirds vocalized the chirp call even when no other birds were present. Thus, a bird might repel potential intruders by advertising its presence. If this signal is not effective, the bird will produce different calls, grouped or singular, and change to aggressive behaviors that culminate with fights and expulsions. In fights, the guttural call was produced, which sounds like an unfriendly grumble and fits within Morton's (1977)

motivational rules as high aggressiveness. In general, Sombre Hummingbird calls were used mostly in defense of a food-centered territory. Similar conclusions have been reached for other trochilines (Stiles 1982; Rusch et al. 1996, 2001; Ornelas et al. 2002). A direct advantage of having territorial vocalizations would be the assurance of access to food and thus reproductive success; good territories make males more attractive to females (Wolf and Stiles 1970).

Rufous-breasted Hermits produced calls once or in call-and-response sequences, rather than in bouts, and mostly during nonagonistic behaviors, making them a quieter species. The $S$ chirp call was produced when flying and foraging, and it may be useful for advertising location to conspecifics. The flight call of the Little Hermit (P. longuemareus; Stiles and Wolf 1979), a phaethornithine, was also suggested as a location indicator. Both S- and M-chirp calls often elicited an answer from nearby perched Rufous-breasted Hermits, usually an M-chirp call, but rarely when the birds were visually close. Thus, these may function as long-distance calls. It is possible that this call-and-response is used to maintain spacing patterns but, if so, it is not used in the territorial manner observed with calls by Sombre Hummingbirds. When rare agonistic interactions occurred, the guttural call was sometimes used by the Rufous-breasted Hermit, but more often the transitional call was used. The latter has syllables of pronounced decreasing frequency, which, according to Morton (1977), is informative of increasing hostility. Interestingly, this call was also produced during long courtship chases (similar to the "chee" call of the Rufous-breasted Hermit in Trinidad [Snow 1973]). A possible explanation is that, as hypothesized for ritualized dive displays of trochiline hummingbirds (Stiles 1982), long chases may have evolved as a sexual attractant from aggressive behavior.

The Sombre Hummingbird's undirected song seems to be used to advertise the presence of a defending bird and to repel potential intruders from a feeding territory. Songs of other trochiline species have been suggested or demonstrated to be produced for territorial defense (Goldberg and Ewald 1991, Ficken et al. 2002, Ornelas et al. 2002). A female attraction function of the undirected song, as reported for the Blue-throated Hummingbird (Ficken et al. 2002), cannot be discounted. However, the directed song of the Sombre Hummingbird seems to have a clearer sexual-attraction function. It is produced with a complex display that involves manipulation of the crissum. Directed song differed from undirected song only by the absence of the introductory syllable in the former. The $i$ syllable, higher pitched and louder than subsequent syllables, can easily be heard. Its function could be to capture the attention of neighbors. In directed song, the singer apparently already has the receiver's attention and, thus, the $i$ syllable may be unnecessary. Differences between the directed and undirected songs have been observed in a songbird, the Zebra Finch (Taenopygia guttata), where directed song to females has more introductory syllables than the undirected song (Sossinka and Böhner 1980).

The Rufous-breasted Hermit song was produced mostly while birds were perched and appears not to be used for food-territory defense, because this species is a trapliner (Snow and Snow 1972). In contrast to other phaethornithines, Rufous-breasted Hermits do not engage in lek 
behavior (Snow 1973, present study), which is usually used to attract mates. We suggest that Rufous-breasted Hermit song may be used to attract mates (but not in leks), given that during a year's observation, song production increased significantly during the beginning of the breeding season (A. Ferreira unpubl. data). For a Rufous-breasted Hermit population in Trinidad, song production was limited almost exclusively to the breeding season (Snow 1973). The incorporation of calls in Rufous-breasted Hermit Song suggests that the bird may sing to communicate various behavioral states. By singing different combinations of call syllables, the bird may be informing its location or friendly contact (sequences of $A$ syllables: M-chirp call), copulation disposition (sequences of $E$ syllables: transitional call; sequences of $B, C, D$, and $F$ syllables: unique to song), and aggressive behavior (sequences of $G$ syllables: guttural call). Incorporation of calls into song has also been reported in Zebra Finches (Zann 1996), where song was suggested to have derived from unlearned calls through their systematic repetition and modification.

In terms of evolution, it has been hypothesized that the Trochilinae and Phaethornithinae subfamilies originated in the lowlands of the American tropics, possibly through competitive interactions of their ancestors, and then the Trochilinae colonized diverse habitats from tropical to temperate areas, while the Phaethornithinae stayed in the tropics and colonized its forests (Bleiweiss 1998). In this scenario, we hypothesize that the pressures of diverse habitats on the Trochilinae selected for territorial vocal behaviors (calls and songs) to make defense of foodcentered territories more effective. Vocalizations produced during territorial defense have been found in basal tropical species (our results for Sombre Hummingbird) as well as in more derived tropical (Ornelas et al. 2002) and temperate trochiline species (Pitelka 1942; Stiles 1982;

Goldberg and Ewald 1991; Rusch et al. 1996, 2001). The pressures of a more constant habitat on the Phaethornithinae may have selected for vocal behavior that makes long-distance interactions possible between conspecifics that are constantly moving through forests. These interactions would be male-female and, for those species that engage in lek behavior (Stiles and Wolf 1979), male-male as well. Vocalizations associated with location, bond-maintenance between mates, and female attraction have been found in basal species (Rufous-breasted Hermit in the present study and in Snow [1973]) as well as in more derived phaethornithine species (Snow 1968, Wiley 1971, Stiles and Wolf 1979).

\section{Acknowledgements}

We thank the staff of Museu de Biologia Professor Mello Leitão for providing natural space and services that made this study possible, O. Tchernichovski for help with SOUND ANALYSIS, and R. Grantsau for drawing the Sombre Hummingbird courtship-behavior figure. We thank K. S. Leon and P. Rousellot for their help in the early stages of this study, and Jarvis laboratory members for critical reading of the manuscript. This research was performed with the approval of Instituto Brasileiro do Meio Ambiente E Dos Recursos Naturais Renováveis (no. 058/97-DIFAS). It was funded by a fellowship from Fundação de Amparo à Pesquisa do Estado de São Paulo (no. 99/00242-5) to A.R.J.F., a National Science Foundation grant (no. IBN0084357) to E.D.J. and C.V.M., and a Packard Foundation Fellowship and Duke University start-up funds to E.D.J. Spectrograms, vocalizations, and pictures used in behavioral scoring are available at jarvislab.net/Evolution/hummingbirdsongs.html. A.R.J.F. dedicates this manuscript to Rolf Grantsau, an authentic and inspiring naturalist.

\section{Literature Cited}

Aubin T, Jouventin P, Hildebrand C. Penguins use the two-voice system to recognize each other. Proceedings of the Royal Society of London, Series B 2000;267:1081-1087. [PubMed: 10885512]

Baptista LF, Schuchmann K-L. Song learning in the Anna Hummingbird (Calypte anna). Ethology 1990;84:15-26.

Bleiweiss R. Origin of hummingbird faunas. Biological Journal of the Linnean Society 1998;65:77-97.

Buzato S, Sazima M, Sazima I. Hummingbird-pollinated fl oras at three Atlantic forest sites. Biotropica 2000;32:824-841. 
Colliaas NE. The vocal repertoire of the Red Junglefowl: A spectrographic classification and the code of communication. Condor 1987;89:510-524.

Ficken MS, Rusch KM, Taylor SJ, Powers DR. Blue-throated Hummingbird song: A pinnacle of nonoscine vocalizations. Auk 2000;117:120-128.

Ficken MS, Rusch KM, Taylor SJ, Powers DR. Reproductive behavior and communication in Bluethroated Hummingbirds. Wilson Bulletin 2002;114:197-209.

Gahr M. Neural song control system of hummingbirds: Comparison to swifts, vocal learning (songbirds) and nonlearning (suboscines) passerines, and vocal learning (budgerigars) and nonlearning (dove, owl, gull, quail, chicken) nonpasserines. Journal of Comparative Neurology 2000;426:182-196. [PubMed: 10982462]

Gaunt AS. An hypothesis concerning the relationship of syringeal structure to vocal abilities. Auk 1983;100:853-862.

Gaunt SLL, Baptista LF, Sánchez JE, Hernandez D. Song learning as evidenced from song sharing in two hummingbird species (Colibri coruscans and C. thalassinus). Auk 1994;111:87-103.

Goldberg TL, Ewald PW. Territorial song in the Anna's Hummingbird, Calypte anna: Costs of attraction and benefits of deterrence. Animal Behaviour 1991;42:221-226.

Grantsau, R. Os beija-flores do Brasil: Uma chave de identificação para todas as formas de beija-flores do Brasil. Editora Expressão e Cultura; Rio de Janeiro: 1988.

Guyomarc'h JC, Guyomarc'h C. Vocal communication in European quail; Comparison with Japanese quail. Comptes Rendus Academy of Sciences Paris 1996;319:827-834.

Hinkelmann C, Schuchmann K-L. Phylogeny of the hermit hummingbirds (Trochilidae: Phaethornithinae). Studies of Neotropical Fauna and Environment 1997;32:142-163.

Hoese WJ, Podos J, Boetticher NC, Nowicki S. Vocal tract function in birdsong production: Experimental manipulation of beak movements. Journal of Experimental Biology 2000;203:1845-1855. [PubMed: 10821742]

Jarvis ED. Learned birdsong and the neurobiology of human language. Annals of New York Academy of Sciences 2004;1016:749-777.

Jarvis ED, Mello CV. Molecular mapping of brain areas involved in parrot vocal communication. Journal of Comparative Neurology 2000;419:1-31. [PubMed: 10717637]

Jarvis ED, Nottebohm F. Motor-driven gene expression. Proceedings of the National Academy of Sciences USA 1997;94:4097-4102.

Jarvis ED, Ribeiro S, da Silva ML, Ventura D, Vielliard J, Mello CV. Behaviourally driven gene expression reveals song nuclei in hummingbird brain. Nature 2000;406:628-632. [PubMed: 10949303]

Kobayashi K, Uno H, Okanoya K. Partial lesions in the anterior forebrain pathway affect song production in adult Bengalese finches. Neuroreport 2001;12:353-358. [PubMed: 11209949]

Morton ES. On the occurrence and significance of motivational-structural rules in some bird and mammals sounds. American Naturalist 1977;111:855-869.

Nottebohm F, Stokes TM, Leonard CM. Central control of song in the canary, Serinus canarius. Journal of Comparative Neurology 1976;165:457-486. [PubMed: 1262540]

Ornelas JF, Jiménez L, González C, Hernández A. Reproductive ecology of distylous Palicourea padifolia (Rubiaceae) in a tropical montane cloud forest. I. Hummingbirds' effectiveness as pollen vectors. American Journal of Botany 2004;91:1052-1060.

Ornelas JF, González C, Uribe J. Complex vocalizations and aerial displays of the Amethyst-throated Hummingbird (Lampornis amethystinus). Auk 2002;119:1141-1149.

Pitelka FA. Territoriality and related problems in North American hummingbirds. Condor 1942;44:189_ 204.

Rusch KM, Thusius K, Ficken MS. The organization of agonistic vocalizations in Ruby-throated Hummingbirds with a comparison to Black-chinned Hummingbirds. Wilson Bulletin 2001;113:425430.

Rusch KM, Pytte CL, Ficken MS. Organization of agonistic vocalizations in Black-chinned Hummingbirds. Condor 1996;98:557-566. 
Ruschi A. A estação ou período de reprodução nos beija-flores. Boletim do Museu de Biologia "Mello Leitão. Série Biologia 1964;42:1-9.

Ruschi, A. Hummingbirds of State of Espírito Santo. Rios Editora; São Paulo, Brazil: 1982.

Scharff C, Nottebohm F. A comparative study of the behavioral defi cits following lesions of various parts of the Zebra Finch song system: Implications for vocal learning. Journal of Neuroscience 1991;11:2896-2913. [PubMed: 1880555]

Schuchmann, K-L. Family Trochilidae (Hummingbirds). In: del Hoyo, J.; Elliott, A.; Sargatal, J., editors. Handbook of the Birds of the World, vol.5: Barn-owls to Hummingbirds. Lynx Edicions; Barcelona, Spain: 1999. p. 468-680.

Snow BK. Social organization of the Hairy Hermit Glaucis hirsuta. Ardea 1973;61:94-105.

Snow BK, Snow DW. Feeding niches of hummingbirds in a Trinidad valley. Journal of Animal Ecology 1972;41:471-485.

Snow DW. The singing assemblies of Little Hermits. Living Bird 1968;7:47-55.

Sossinka R, Böhner J. Song types in the Zebra Finch (Poephila guttata castanotis). Zeitscrift für Tierpsychologie 1980;53:123-132.

Stiles FG. Aggressive and courtship displays of the male Anna's Hummingbird. Condor 1982;84:208225.

Stiles FG, Wolf LL. Ecology and evolution of lek mating behavior in the Long-Tailed Hermit Hummingbird. Ornithological Monographs. 1979no. 27

Suthers RA. Peripheral control and lateralization of birdsong. Journal of Neurobiology 1997;33:632652. [PubMed: 9369464]

Tchernichovski O, Nottebohm F, Ho CE, Pesaran B, Mitra PP. A procedure for an automated measurement of song similarity. Animal Behaviour 2000;59:1167-1176. [PubMed: 10877896]

Vallet E, Beme I, Kreutzer M. Two-note syllables in canary songs elicit high levels of sexual display. Animal Behaviour 1998;55:291-297. [PubMed: 9480696]

Vielliard J. Catálogo sonográfi co dos cantos e piados dos beija-flores do Brasil. Boletim do Museu de Biologia “Mello Leitão” Série Biologia 1983;58:1-20.

Wiley RH. Song groups in a singing assembly of Little Hermits. Condor 1971;73:28-35.

Wolf LL. Female territoriality in a tropical hummingbird. Auk 1969;86:490-504.

Wolf LL, Stiles FG. Evolution of pair cooperation in a tropical hummingbird. Evolution 1970;24:759773.

Zann, RA. Vocalizations. In: Perrins, CM., editor. The Zebra Finch: A Synthesis of Field and Laboratory Studies. Oxford University Press; New York: 1996. p. 196-247. 

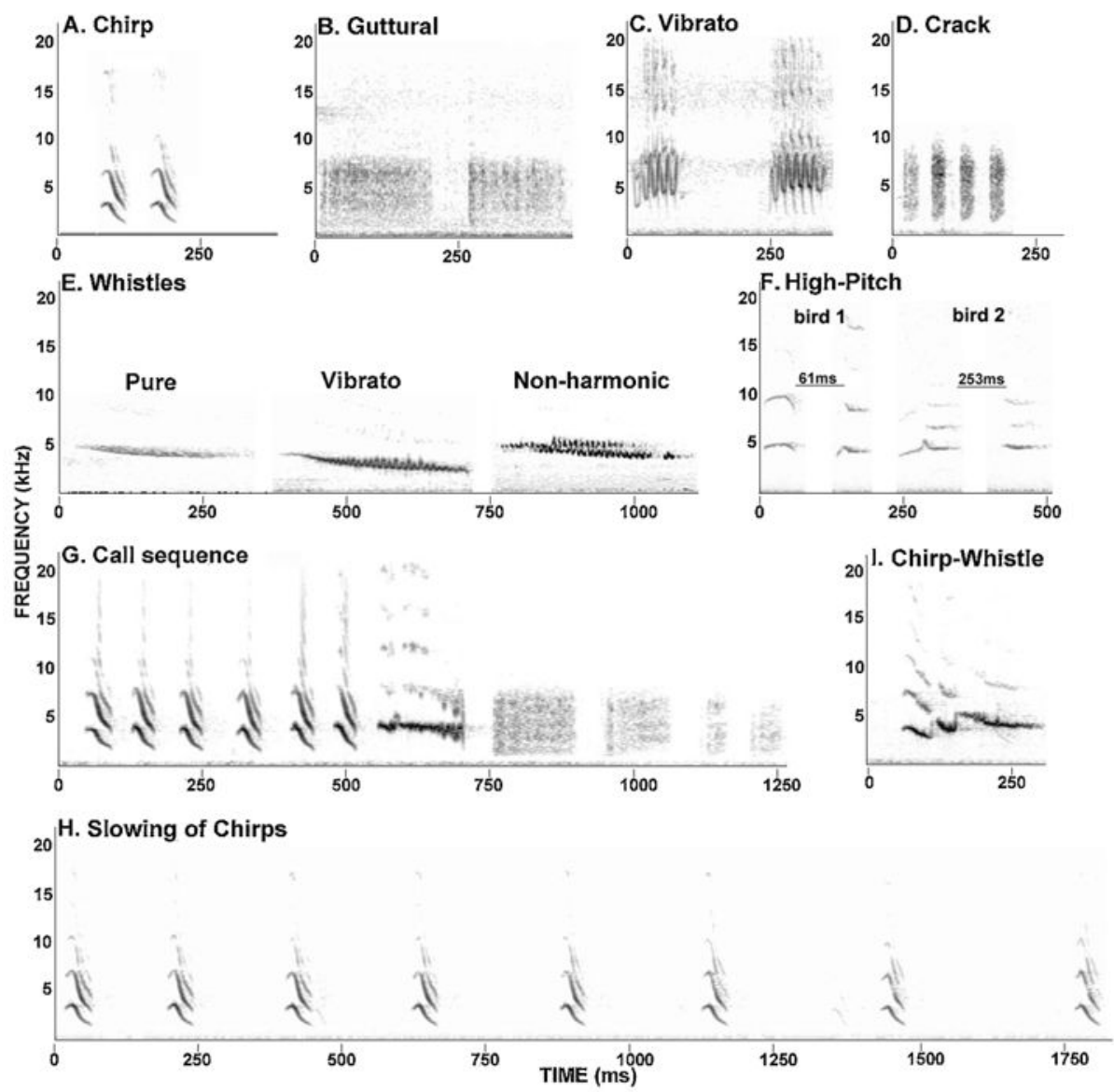

Fig. 1.

Spectrograms of Sombre Hummingbird calls (A-F). In (F), silent intervals between calls were shortened by the time indicated in milliseconds. $(\mathrm{G})$ A call sequence produced by a bird during a confrontation with a conspecific; the harmonics in the whistle (between the chirp and guttural) are attributable to distortion of its loud volume in this recording. $(\mathrm{H})$ Sequence produced by the bird in (A) after an aggressive encounter. (I) Fused call produced by a bird when taking off to expel an intruder. 

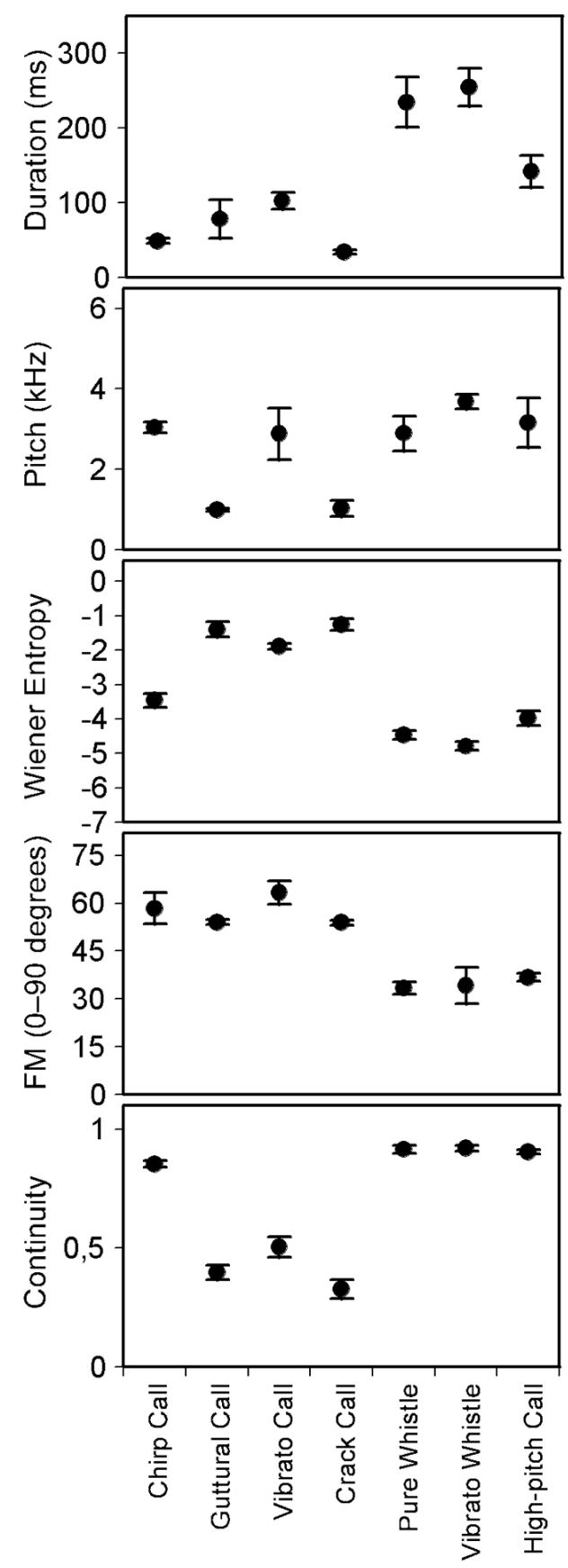

Fig. 2.

Acoustic features of Sombre Hummingbird calls calculated with SOUND ANALYSIS. For the chirp, guttural, and vibrato calls, samples are from different individuals $(n=5,4$, and 5, respectively; 5 syllables per bird). For all other calls, samples are from individuals that could not be identified ( rack $=10$, pure whistle $=12$, vibrato whistle $=26$, and high pitch $=4$ birds; 5 syllables bird per bird). Nonharmonic whistles were rarely recorded and, therefore, were not analyzed. Differences mentioned in the text are statistically significant $(t$-test, $P<0.05)$. Plotted values represent means $\pm \mathrm{SE}$. 

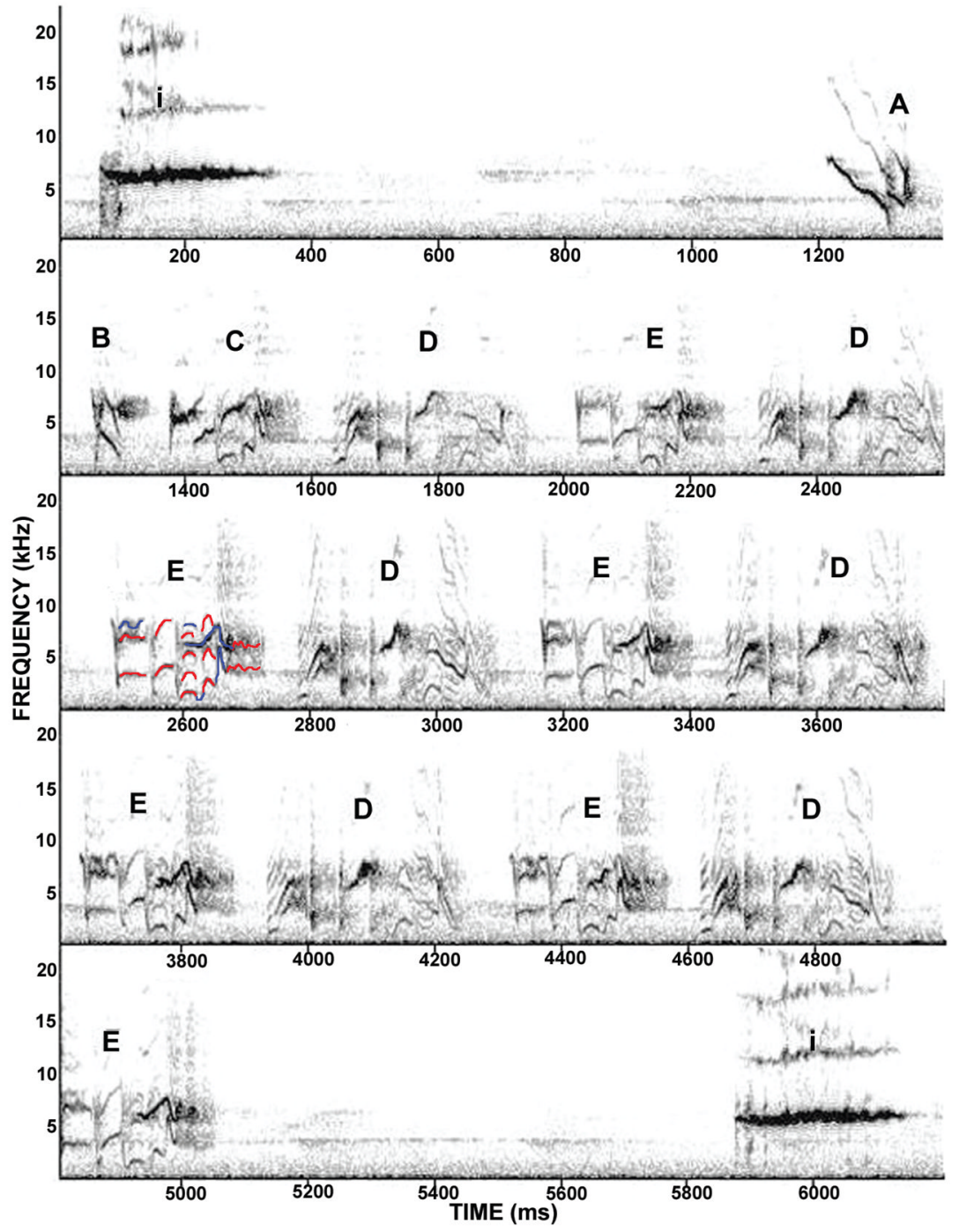

Fig. 3.

Bout of undirected song produced by a Sombre Hummingbird individual while on its principal perch. Colored lines in one $E$ syllable depict nonrelated harmonics, likely a result of the twovoice phenomenon. Same-colored lines depict related harmonics. 


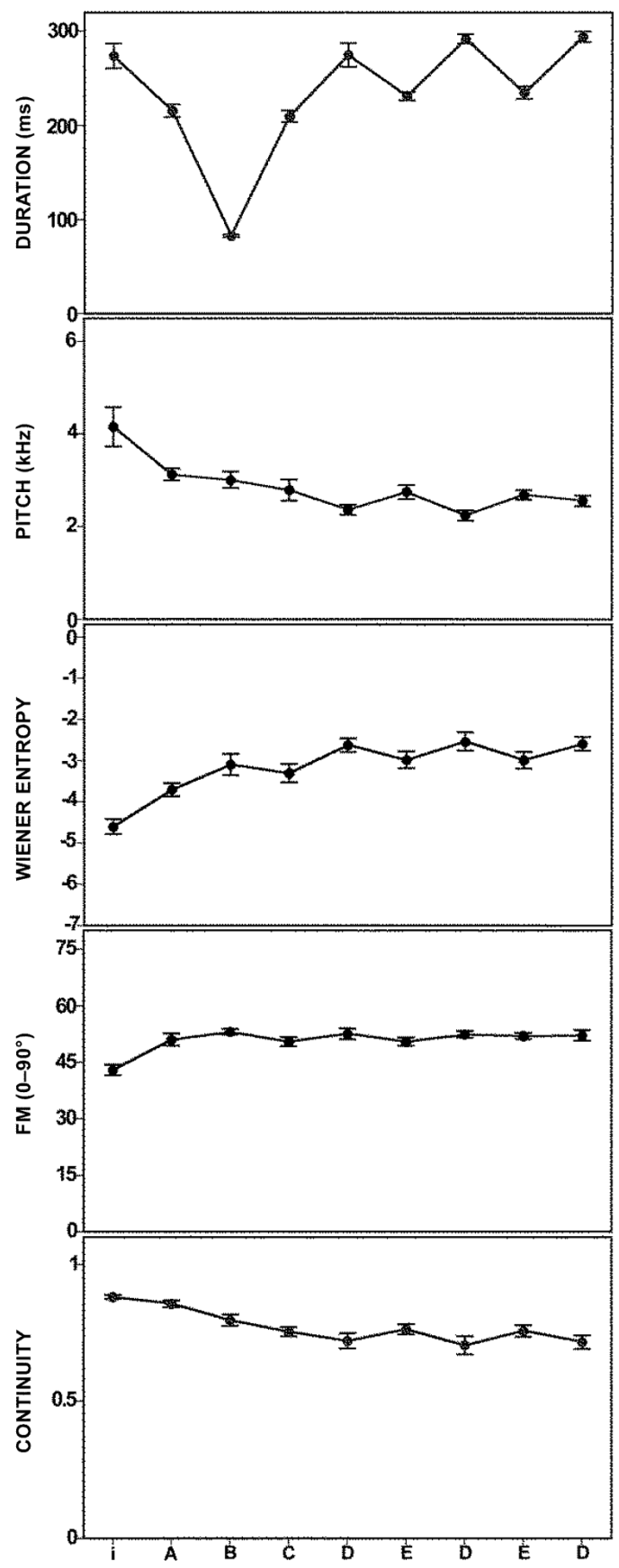

Fig. 4.

Acoustic features of Sombre Hummingbird song syllables calculated with SOUND

ANALYSIS. Syllables $i$ and $D$ had the longest and $B$ the shortest duration; $i$ had the highest and $D$ the lowest pitch; $D$ had the highest (noisier sound) and $i$ the lowest (purer sound) Wiener entropy; $i$ had the lowest and others had similar FM; $i$ and $A$ had the highest and others had similar continuity. Samples are from five individuals ( 5 song motifs per bird; total sample of syllables: $i-E 1=19, D 2=18, E 2=13, D 3=12$; differences mentioned are statistically significant; $t$-test, $P<0.05$ ). Values represent means \pm SE and were plotted in the order in which the syllables occur in the song. 
A.

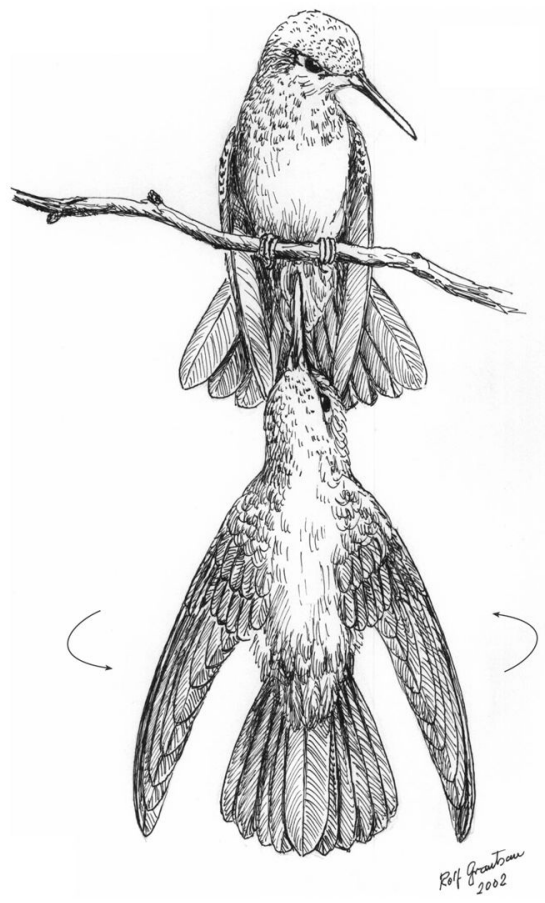

B.

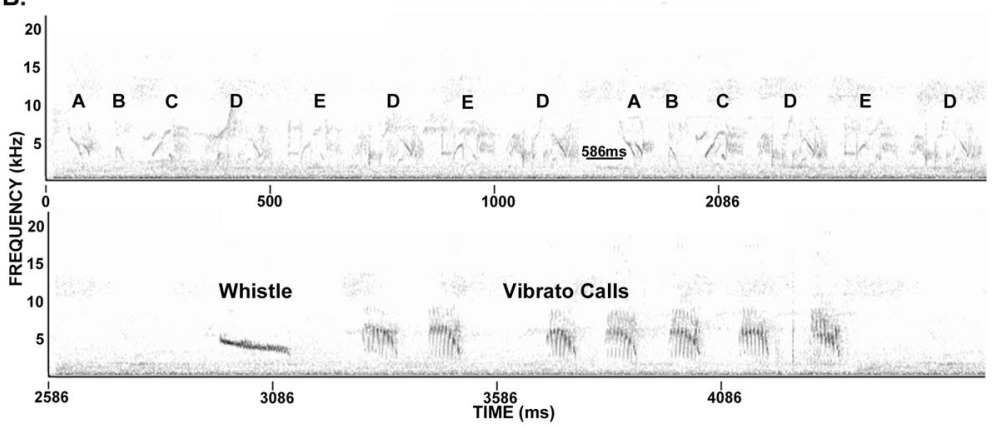

Fig. 5.

Directed singing behavior. (A) Drawing of courtship display (by Rolf Grantsau). The male hangs by the female's crissum, sways from side to side (arrows), and sings, while the female is perched. (B) End of a bou. of directed song (upper trace) produced by an individual during the courtship display, followed by a whistle call produced by the perched bird, and vibrato calls (lower trace) produced by one of the birds during subsequent interactions while flying. The silent interval between song motifs was reduced to the amount of time indicated on the graph. The directed song is produced at lower amplitude than the undirected song. 

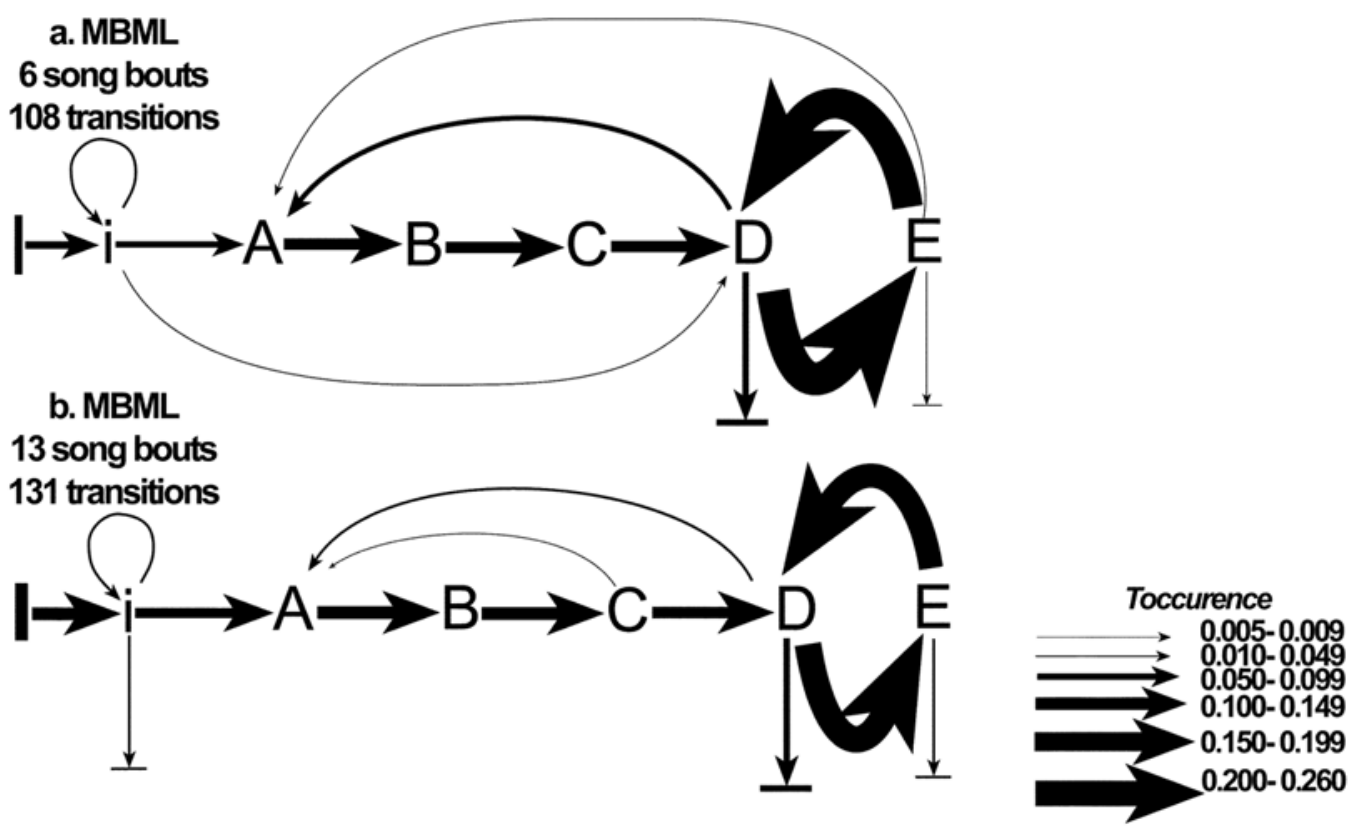

Fig. 6.

(A-B) Sombre Hummingbird song syntax diagrams from representative individuals, demonstrating that song syntax is similar and quite stereotyped within and between birds. The legend (bottom right) shows the $T_{\text {occurrence }}$ value ranges. Bars represent silence at the beginning or end of bouts. 


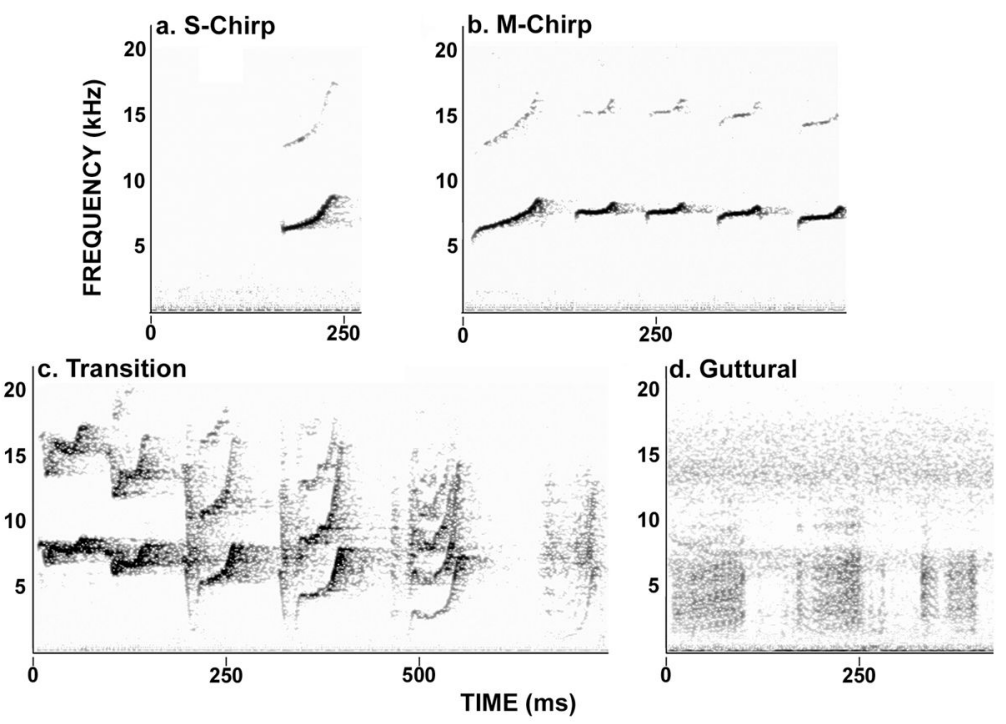

Fig. 7.

Spectrograms of Rufous-breasted Hermit calls. The guttural call was produced by a Rufousbreasted Hermit while expelling a heterospecific hummingbird that was preventing it from feeding. 

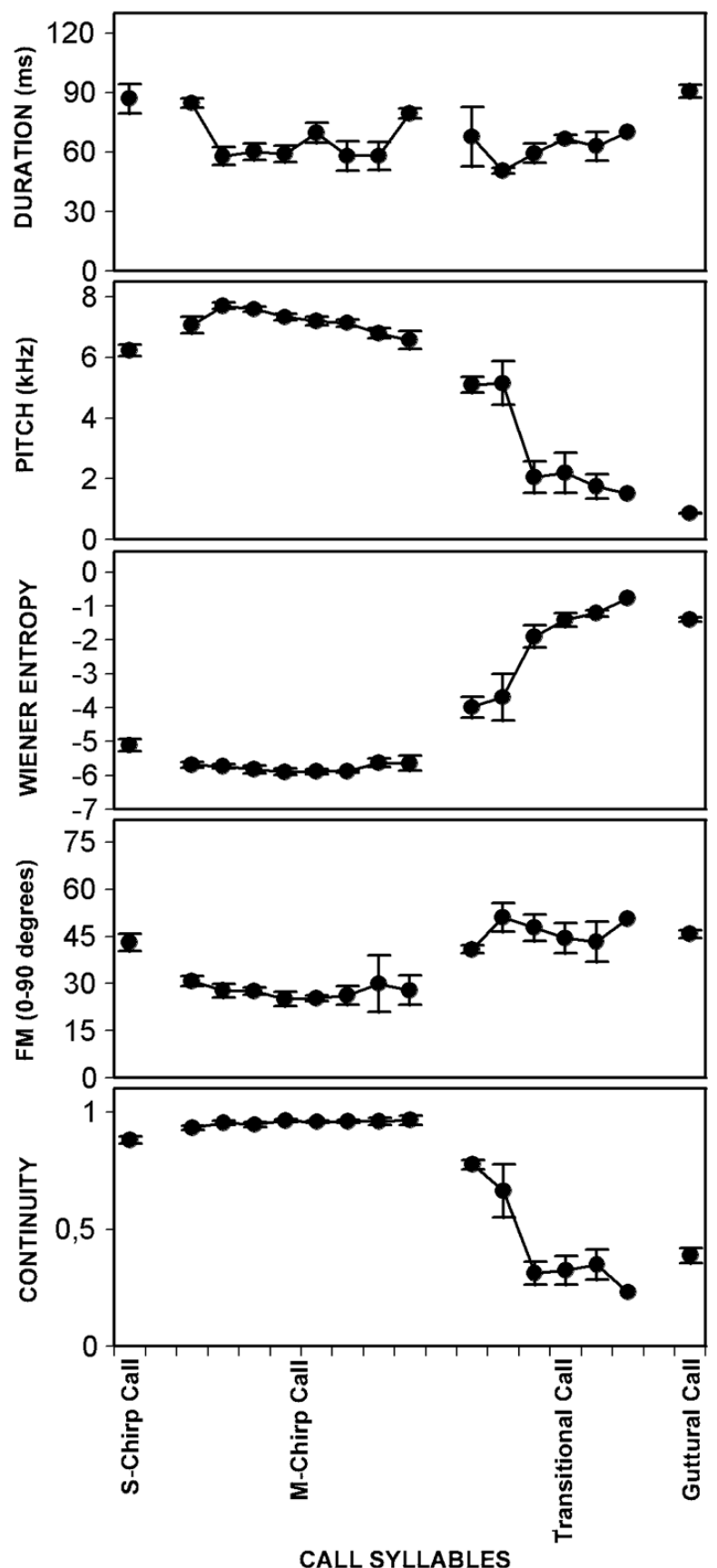

Fig. 8.

Acoustic features of Rufous-breasted Hermit calls calculated with SOUND ANALYSIS. Mchirp and transitional calls are, respectively, series of 4-8 and 5-8 syllables of the same class. In cases where the 7th and 8th syllables of transitional calls were produced, their recordings were of low quality and could not be used for calculations of acoustic features. Samples are from recordings of individuals that could not be identified: S-chirp $=12$; M-chirp (1st-8th syllables) $=9,9,9,8,8,4,2$, and 2 ; transitional (1st-6th syllables) $=3,3,3,3,3$, and 1 ; guttural $=8$ birds. Transitioning of acoustic feature differences mentioned in the main text are significantly different $(t$-test, $P<0.05)$. Values plotted represent means $\pm \mathrm{SE}$. 


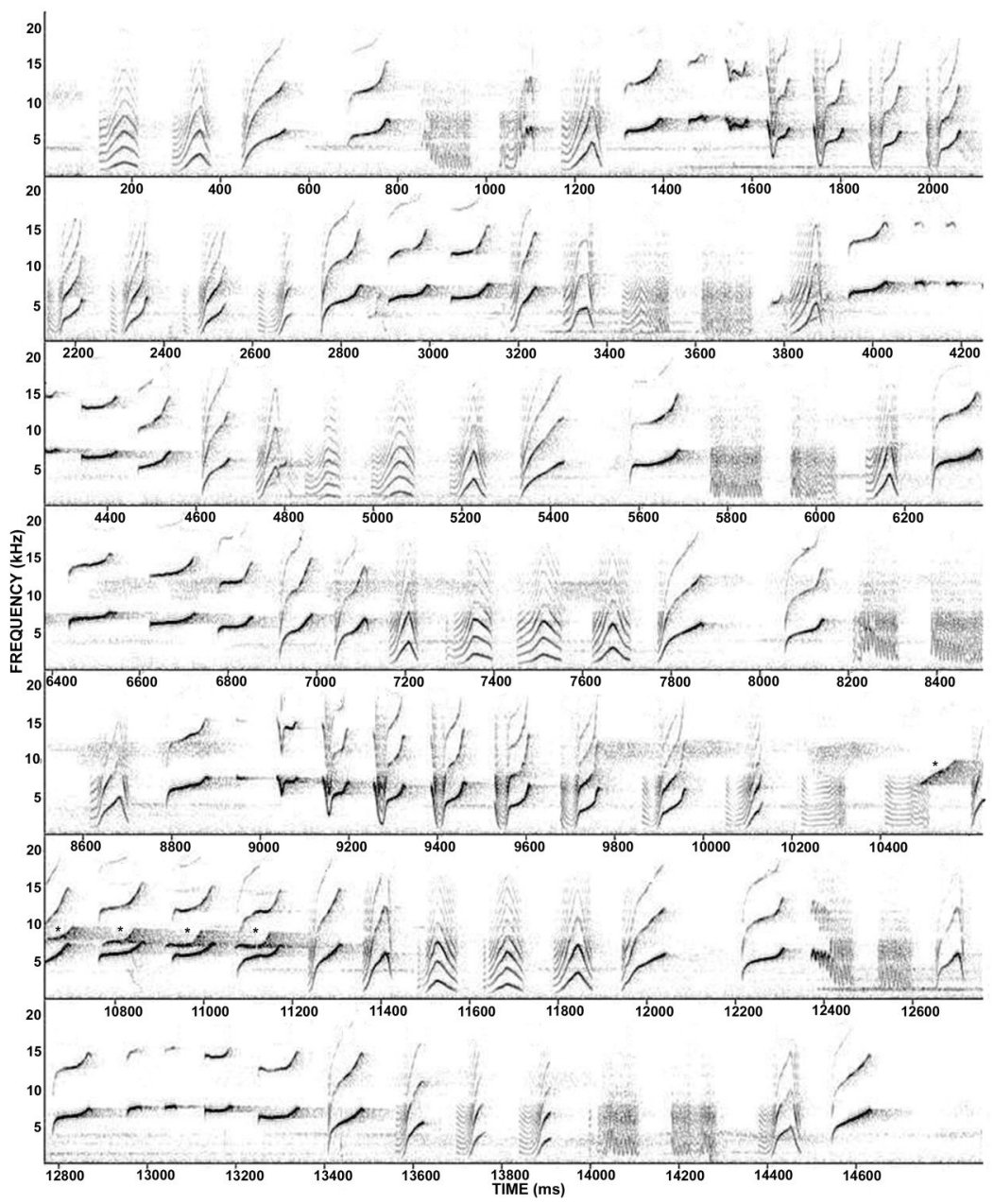

Fig. 9.

Song of Rufous-breasted Hermit vocalized by a perched bird at the MBML. Asterisks indicate syllables that overlapped with an M-chirp call from another individual. 


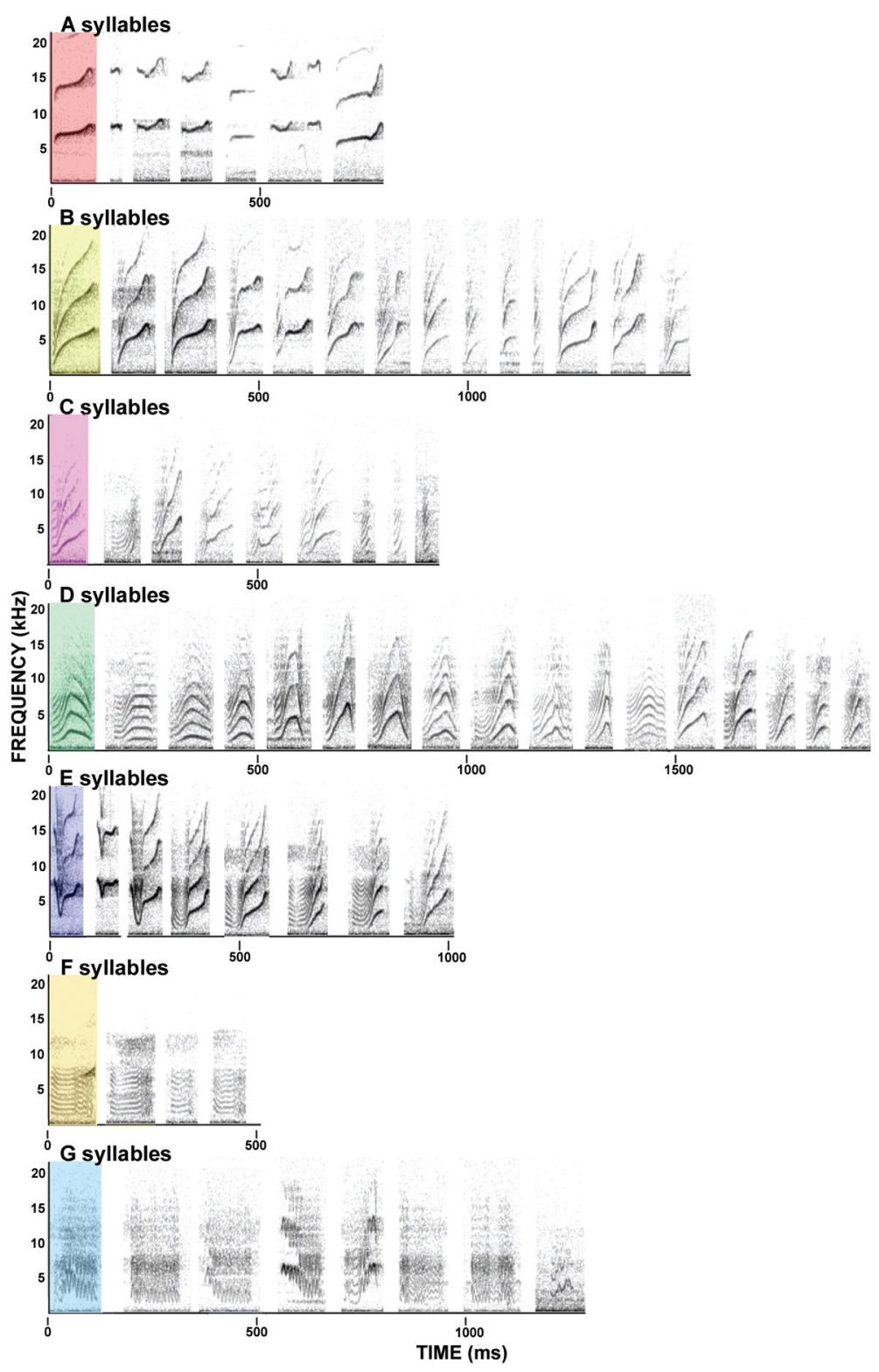

Fig. 10.

Syllable classes of Rufous-breasted Hermit song. The rightmost syllable of each row is the representative example chosen to define each category. A syllables: a fundamental frequency and harmonic with or without modulation; similar to the syllables of S- and M-chirp calls. $B$ syllables: a fundamental and two harmonics that typically initiate and terminate with a rapidly ascending frequency modulation. $C$ syllables: similar to $B$, but lower in pitch and richer in harmonics, particularly at their onset, followed by a steep rise in frequency. $D$ syllables: modulated harmonic stacks with a bell-like shape. $E$ syllables: start with rapid descending and ascending frequency modulations and contain several harmonics, resulting in a distorted V-or U-shape; similar to the syllables of the transitional call. $F$ syllables: flat and dense harmonic stacks, with a tendency to be modulated at the end. $G$ syllables: stacks of rapid frequency, modulated structures with a broad frequency band so that the overall structure approaches broadband noise. 

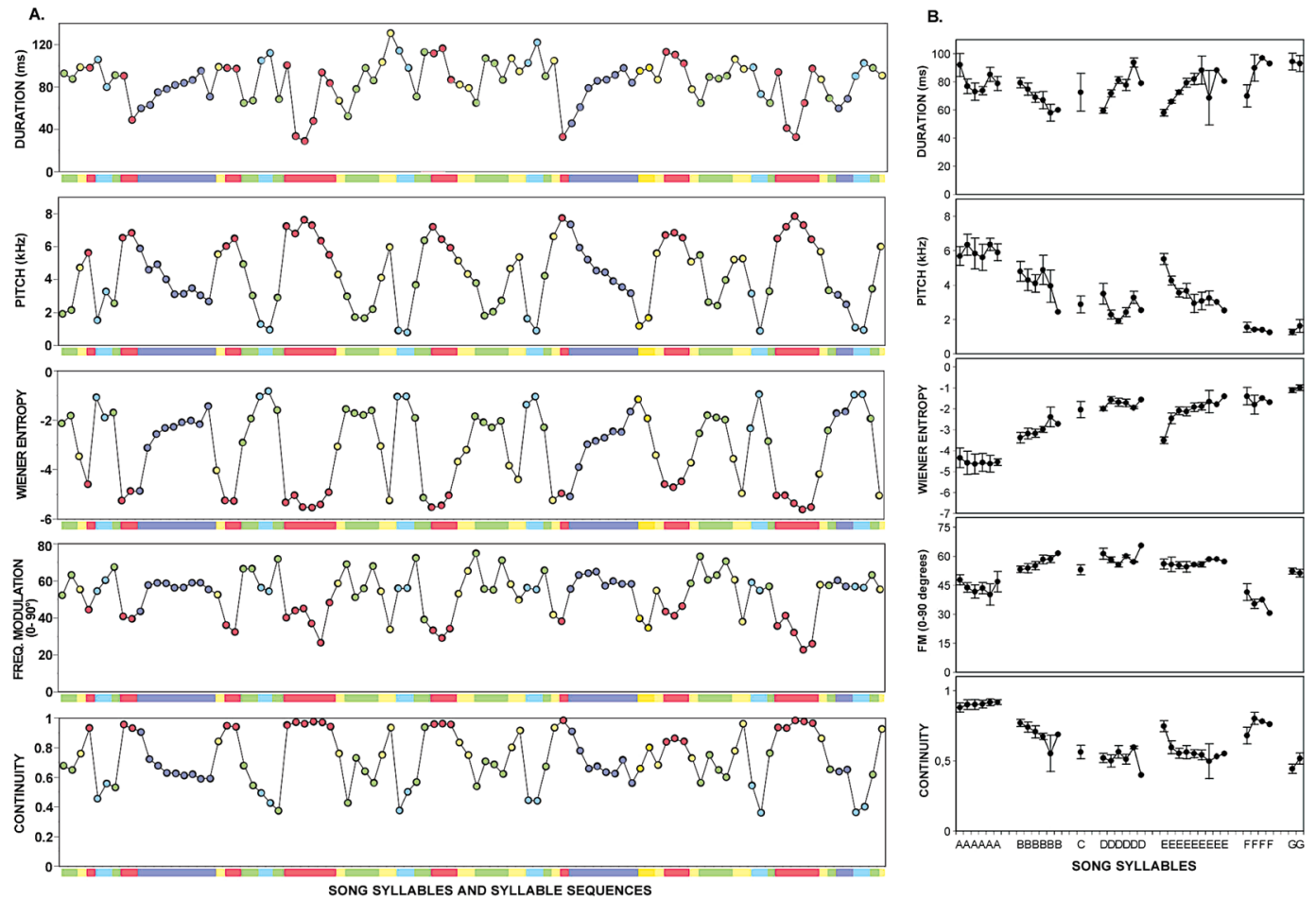

Fig. 11.

(A) Acoustic features of one representative song bout of Rufous-breasted Hermit. Each dot represents a syllable. The colors of dots and bars below each graph represent the syllable classes as in Figure 10. All features, with the possible exception of duration, cycle in their values. (B) Acoustic features of Rufous-breasted Hermit song syllables calculated with SOUND ANALYSIS. Syllables of the same class are plotted in the order they were produced in the song. Syllables of the $A, E, F$, and $G$ classes had the longest duration; $B, D$, and $E$ had the shortest duration; $A$ had the highest pitch; $F$ and $G$ had the lowest pitch; $G$ had the highest (noisier sound) and $A$ the lowest (purer sound) Wiener entropy; $B$ and $D$ had the highest and $F$ the lowest FM; $A$ had the highest continuity; $D$ and $G$ had the lowest continuity. Samples are from four different individuals ( $2-4$ song motifs per bird; total sample sizes: $A(1$ st -6 th $)=$ $21,14,17,12,5,2 ; B(1$ st-6th $)=22,16,10,6,2,1 ; C=13 ; D(1$ st -6 th $)=23,23,20,16,3,1$; $E(1 \mathrm{st}-9$ th $)=16,15,15,14,12,10,6,3,2 ; F(1 \mathrm{st}-4$ th $)=10,7,1,1 ; G(1 \mathrm{st}-2$ nd $)=16$ and 8 . Values represent means $\pm \mathrm{SE}$. 

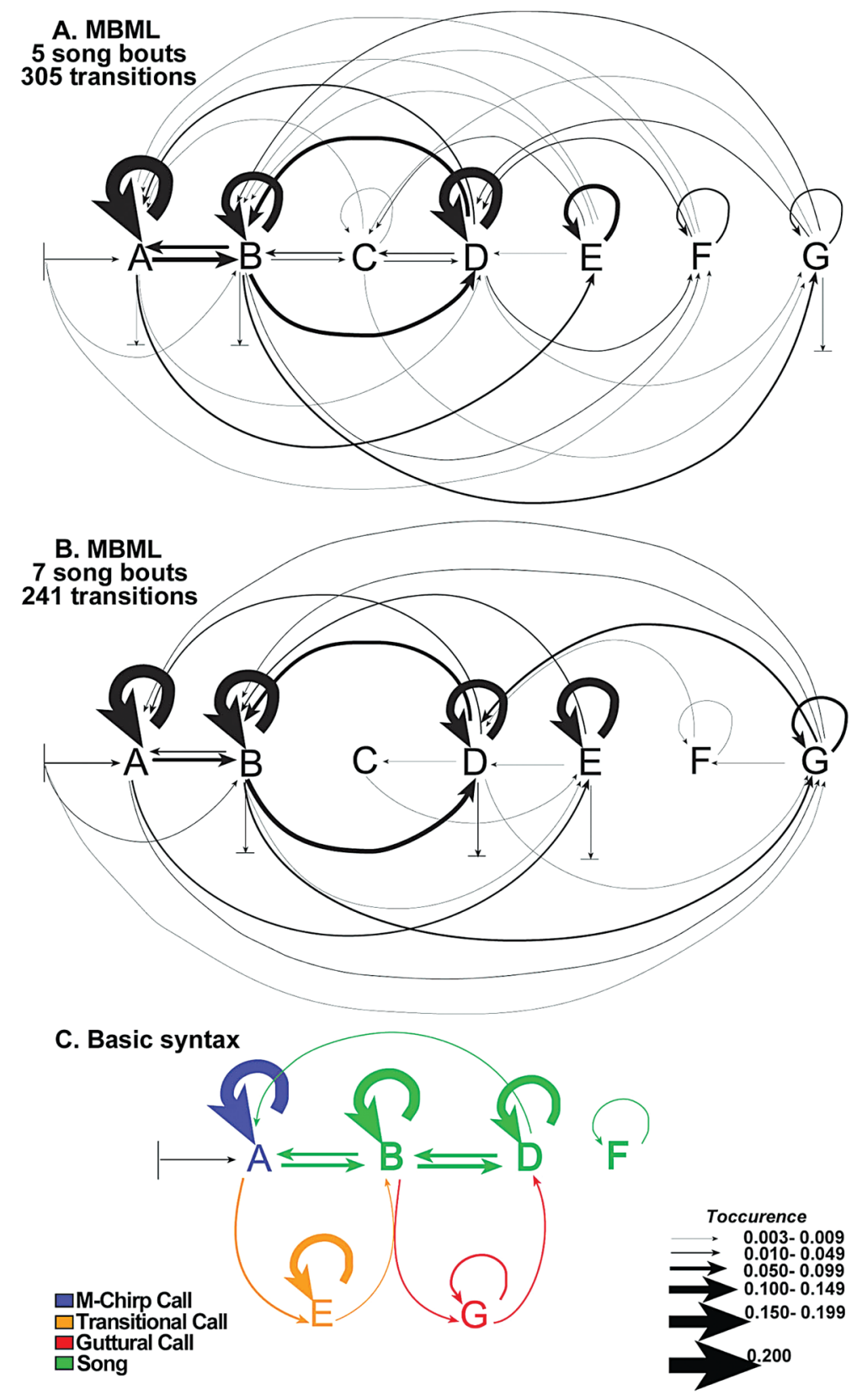

Fig. 12.

Rufous-breasted Hermit song syntax. (A-B) Syntax diagrams from representative individuals, demonstrating that song syntax is variable within and between birds. (C) Basic song syntax. Although transitions between repeated syllables of class $F$ were common, all transitions to $F$ syllables from other classes were below the $1 \%$ cut-off and, thus, no arrow is shown to the $F$ group. Colors other than green indicate segments of song that are similar to calls. 


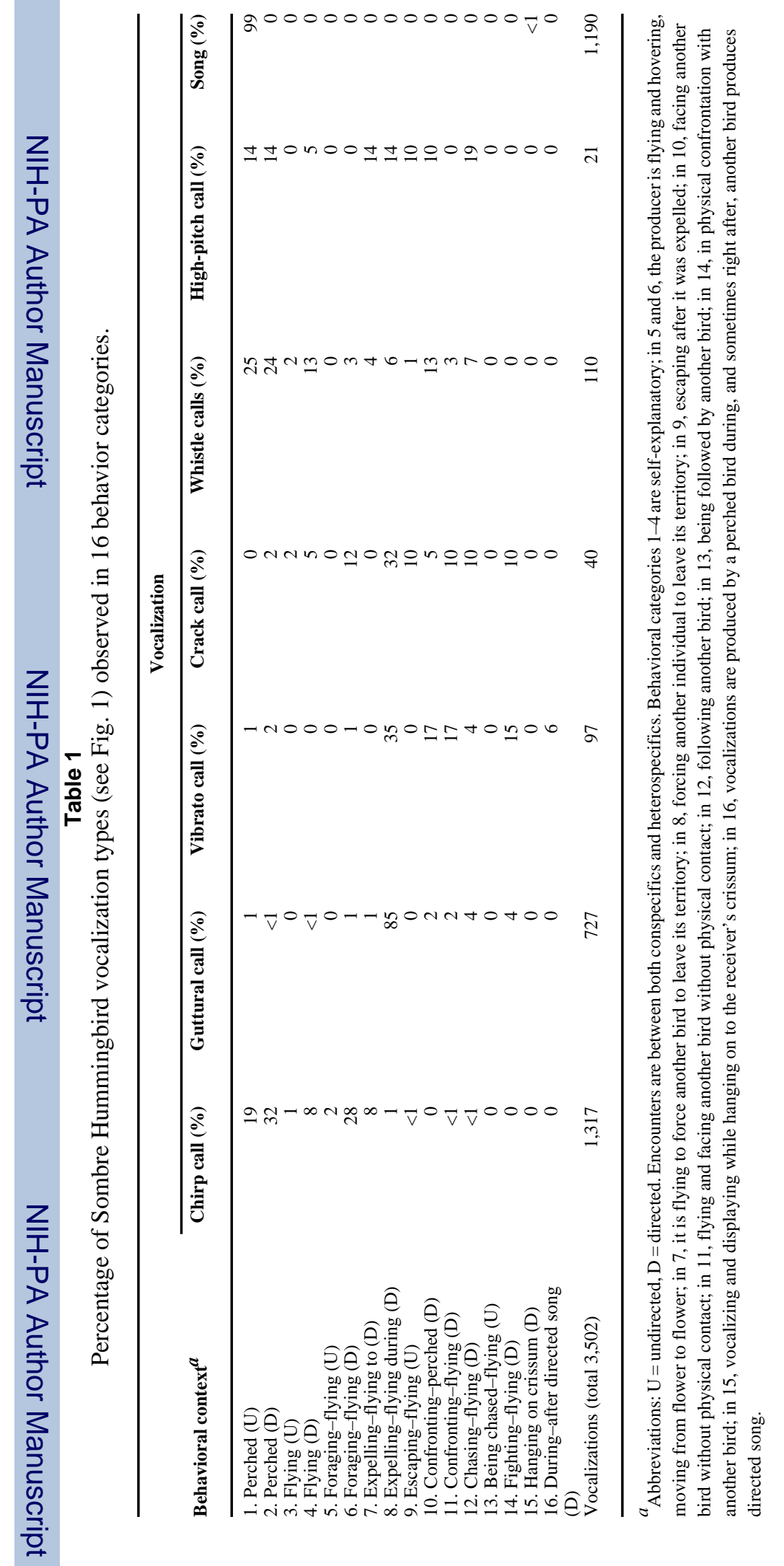

Auk. Author manuscript; available in PMC 2008 September 18. 
Table 2

Percentage of Rufous-breasted Hermit vocalization types (see Fig. 7) observed in 17 behavior categories.

\begin{tabular}{|c|c|c|c|c|}
\hline \multirow[b]{2}{*}{ Behavioral context } & \multicolumn{4}{|c|}{ Vocalization } \\
\hline & S-chirp call $(\%)$ & M-chirp call (\%) & Transitional call (\%) & Song $(\%)$ \\
\hline 1. Perched (U) & 3 & 70 & 0 & 0 \\
\hline 2. Perched (D) & 1 & 3 & 6 & 99 \\
\hline 3. Flying (U) & 2 & 0 & 2 & 0 \\
\hline 4. Flying (D) & 59 & 0 & 8 & $<1$ \\
\hline 5. Foraging-flying $(\mathrm{U})$ & 31 & 0 & $<1$ & 0 \\
\hline $\begin{array}{l}\text { 6. Response to the S-chirp call- } \\
\text { perched (U) }\end{array}$ & 1 & 14 & 0 & 0 \\
\hline $\begin{array}{l}\text { 7. Response to the M-chirp call- } \\
\text { perched (U) }\end{array}$ & $<1$ & 10 & 0 & 0 \\
\hline 8. Response to the song-perched (U) & $<1$ & 3 & 0 & 0 \\
\hline 9. Expelling-flying (D) & 0 & 0 & 8 & 0 \\
\hline 10. Escaping-flying (U) & 0 & 0 & 4 & 0 \\
\hline 11. Confronting-perched (D) & 0 & 0 & 1 & 0 \\
\hline 12. Confronting-flying (D) & 0 & 0 & 7 & 0 \\
\hline 13. Chasing-flying (D) & $<1$ & 0 & 11 & 0 \\
\hline 14. Short chase-flying (D) & 0 & 0 & 36 & 0 \\
\hline 15. Long chase-flying (D) & 0 & 0 & 4 & 0 \\
\hline 16. Being chased-flying (U) & 1 & 0 & 9 & 0 \\
\hline 17. Fighting-flying (D) & 0 & 0 & 2 & 0 \\
\hline Vocalizations (total 761) & 326 & 71 & 156 & 208 \\
\hline
\end{tabular}

${ }^{a}$ Abbreviations: $\mathrm{U}=$ undirected, $\mathrm{D}=$ directed. Encounters are between both conspecifics and heterospecifics. Behavioral categories $1-4$ are selfexplanatory; in 5, the producer is flying and hovering, moving from flower to flower (traplining behavior); in 6, the call is produced immediately after another bird's S-chirp call; in 7, immediately after another bird's M-chirp call; in 8, immediately after another bird's song; in 9, the producer's behavior forces another individual to leave its territory; in 10, the producer escapes after being expelled by a bird; in 11, it is perched and facing another bird without physical contact; in 12, it is flying and facing another bird without physical contact; in 13, it is chasing another bird (Rufous-breasted Hermit or other); in 14, two Rufous-breasted Hermits engage in a short-distance chase (a few meters) of short duration (seconds); in 15, two Rufous-breasted Hermits engage in a long-distance chase (many meters) of longer duration (minutes); in 16, the producer is being followed by another bird; in 17, it is in physical confrontation with another bird. 